\title{
Interprofessional Inconsistencies in the Diagnosis of Shoulder Instability: Survey Results of Physicians and Rehabilitation Providers
}

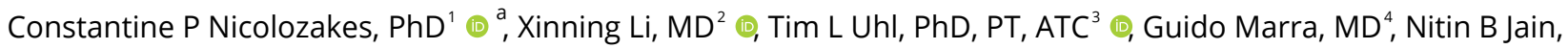
MD, MSPH ${ }^{5}$, Eric J Perreault, $\mathrm{PhD}^{6} \mathbb{0}$, Amee L Seitz, PT, DPT, PhD ${ }^{7}$ (1)

${ }^{1}$ Biomedical Engineering, Northwestern University; Shirley Ryan AbilityLab; Northwestern University Feinberg School of Medicine, ${ }^{2}$ Orthopaedic Surgery, Boston Medical Center, ${ }^{3}$ Rehabilitation Science, University of Kentucky, ${ }^{4}$ Orthopaedic Surgery, Northwestern University Feinberg School of Medicine, 5 Physical Medicine \& Rehabilitation, UT Southwestern Medical Center, 6 Biomedical Engineering, Northwestern University; Shirley Ryan AbilityLab, ${ }^{7}$ Physical Therapy \& Human Movement Sciences, Northwestern University Feinberg School of Medicine

Keywords: sulcus sign, shoulder instability, rotator cuff impingement, multidirectional instability

https://doi.org/10.26603/001c.25170

\section{International Journal of Sports Physical Therapy}

Vol. 16, Issue 4, 2021

\section{Background}

Clinicians of many specialties within sports medicine care for athletes with shoulder instability, but successful outcomes are inconsistent. Consistency across specialties in the diagnosis of shoulder instability is critical for care of the athlete, yet the extent of divergence in its diagnosis is unknown.

\section{Hypothesis}

Physicians differ from rehabilitation providers in which findings they deem clinically important to differentiate shoulder instability from impingement, and in how they diagnose athlete scenarios with atraumatic shoulder instability.

\section{Study Design}

Cross-sectional study.

\section{Methods}

Physicians (orthopaedic surgeons, primary care sports medicine physicians) and rehabilitation providers (physical therapists, athletic trainers) were asked via an online survey to rate clinical factors used to diagnose shoulder instability. Clinicians were also asked to diagnose two athlete scenarios with concurrent clinical findings of atraumatic shoulder instability and impingement, differentiated by the absence or presence of a positive sulcus sign.

\section{Results}

Responses were recorded from 888 clinicians. Orthopaedic surgeons $(\mathrm{N}=170)$ and primary care sports medicine physicians $(\mathrm{N}=108)$ ranked physical examination factors as more important for the diagnosis of shoulder instability than patient history factors, whereas physical therapists $(\mathrm{N}=379)$ and athletic trainers $(\mathrm{N}=231)$ preferred patient history factors. Orthopaedic surgeons differed from physical therapists and athletic trainers in their clinical diagnoses for both scenarios $(P \leqslant 0.001)$.

\footnotetext{
a Corresponding author:

Constantine P. Nicolozakes, PhD.

Shirley Ryan AbilityLab.

355 E Erie Street, Floor 21

Chicago IL, 60611

Email: constantine.nicolozakes@northwestern.edu.

Phone: 312-238-0956.
} 


\section{Conclusion}

A lack of consistency exists among sports medicine clinicians in recognizing which

clinical factors are important when used to diagnose shoulder instability and in diagnoses given with concurrent findings of impingement.

\section{Level of Evidence}

Level 3.

\section{INTRODUCTION}

Shoulder instability, defined as "the loss of shoulder comfort and function due to undesirable translation of the humeral head on the glenoid", 1 affects active individuals such as athletes, ${ }^{2-5}$ military personnel, ${ }^{6,7}$ and manual wheelchair users ${ }^{8}$ who use their upper extremity in highdemand activities. Shoulder instability of atraumatic etiology is more difficult to diagnose than traumatic shoulder instability due to the absence of any causal injury. ${ }^{9}$ Rehabilitation programs, commonly recommended as first-line treatment for athletes with atraumatic shoulder instability, ${ }^{10}$ have produced improved short-term outcomes in terms of pain and function compared to previously established protocols. ${ }^{11}$ However, persistent shoulder disability following rehabilitation remains up to eight years after initial diagnosis. ${ }^{12}$ Only $69-76 \%$ of athletes with atraumatic instability who proceed to surgery after failed rehabilitation return to their respective sports at a pre-injury level. ${ }^{13-16}$

Inconsistencies in the clinical diagnosis of shoulder instability between clinical specialties within a sports medicine team are suboptimal for comprehensive collaborative care of the athlete. While variation in the diagnosis of atraumatic shoulder instability has been demonstrated among orthopaedic surgeons, ${ }^{17}$ the diagnostic criteria used by other specialties within sports medicine, including nonsurgical sports medicine physicians, physical therapists, and athletic trainers, have yet to be explored. Consistency across clinical specialties in the diagnosis of shoulder instability is necessary to coordinate care among all clinicians, any of whom may be the first point of diagnosis or treatment for athletes with shoulder instability. ${ }^{18,19}$ However, differences between sports medicine specialties in clinical training and types of ways through which they interact with injured athletes may affect the uniformity in the criteria used to diagnose shoulder instability.

The purpose of this study was to investigate differences in clinical perspectives among physicians and rehabilitation providers in criteria used to diagnose shoulder instability. We hypothesized that orthopaedic surgeons and primary care sports medicine physicians would differ from physical therapists and athletic trainers in which criteria they believe are important to differentiate shoulder instability from rotator cuff impingement. We further hypothesized that sports medicine clinicians would differ in how they diagnose athlete scenarios with atraumatic shoulder instability. We tested our hypothesis by administering an online survey to different specialties of sports medicine clinicians who diagnose and treat patients with shoulder instability.

\section{METHODS}

\section{SURVEY CONTENTS}

A survey instrument was created to assess how clinicians interpret varying history and examination findings to diagnose shoulder instability. The survey's content was developed by an interdisciplinary research team that included orthopaedic surgeons, physiatrists, physical therapists, and athletic trainers. The survey was pilot tested among physicians and rehabilitation providers at the institution hosting the study, and suggestions to improve the clarity and functionality of the survey were incorporated. The survey was designed to be completed in 5-10 minutes.

The survey contained two categories of questions regarding the diagnosis of shoulder instability. First, participants rated the importance of fifteen clinical factors that have been described in the literature to be associated with identifying shoulder instability and rotator cuff impingement (Figure 1A)..$^{20-22}$ Participants rated each clinical factor on a 5-point Likert scale in its importance to differentially diagnose shoulder instability versus rotator cuff impingement, and each factor was rated independently from all other factors. The fifteen clinical factors were grouped after the survey into patient history factors or physical examination factors. Second, participants were asked to diagnose two athlete scenarios with history and examination findings consistent with atraumatic instability and rotator cuff impingement (Figure 1B). Scenarios 1 and 2 were only differentiated by a negative or positive sulcus sign, respectively. Participants chose from four diagnoses in each scenario such that all were possible diagnoses: secondary impingement, unidirectional instability, multidirectional instability, and other. If a participant chose "other" as a diagnosis for a given scenario, they were prompted to provide a short response describing their alternative choice. Participants were also asked what percentage of their new patients with shoulder pain present with signs and symptoms consistent with scenarios 1 and 2.

Participants were asked to answer additional demographic questions, which included their primary specialty, practice setting, sex, and years of experience practicing within their primary specialty. All survey materials were approved prior to survey distribution by the Institutional Review Board at Northwestern University (STU00207355). Participants answered eligibility screening questions and provided online consent before participating in the study and completed all components using electronic data capture tools (REDCap; Qualtrix). ${ }^{23,24}$ Inclusion criteria were as follows: (i) licensed and/or certified physician, physical therapist, or athletic trainer; (ii) clinician who currently practices in clinical care; and (iii) clinician who treats/diagnoses individuals with shoulder instability. Participants 
were excluded if they exited the survey prior to completion.

\section{SURVEY DISTRIBUTION}

Between October 2018 and June 2019, the finalized survey was emailed to physicians (orthopaedic surgeons, primary care sports medicine physicians) and rehabilitation providers (physical therapists, athletic trainers) through the following professional organizations: American Orthopaedic Society for Sports Medicine (sent to approximately 3316 members), American Shoulder and Elbow Surgeons (856 members), American Medical Society for Sports Medicine (3913 members), American Academy of Physical Medicine \& Rehabilitation (3642 members), American Society of Shoulder and Elbow Therapists (111 members), American Academy of Sports Physical Therapy (8500 members), Academy of Orthopaedic Physical Therapy (17592 members), and National Athletic Trainers' Association (5000 members). Additionally, investigators on the study emailed potential participants and advertised through the social media accounts of departments associated with the host institution. Respondents practicing in emergency medicine, family medicine, internal medicine, pediatrics, and physical medicine \& rehabilitation were grouped collectively as primary care sports medicine physicians. Respondents practicing in orthopaedic surgery could indicate if they were a shoulder specialist or practiced within another or no specialty.

\section{STATISTICAL ANALYSES}

Data were analyzed using MATLAB statistical packages (version R2020a; MathWorks). Likert-type clinical factor ratings were analyzed as non-parametric statistics. ${ }^{25}$ Kruskal-Wallis tests were used to test for differences between all specialties in the rated importance of each clinical factor. If significant group differences were observed, Tukey post-hoc tests were used to evaluate the differences between individual specialties in the rated importance of a single clinical factor. Cross tabulations ( $4 \times 2$ contingency tables) were used to test for differences in scenario diagnosis between specialties (within a scenario) and between scenarios (within a specialty). All statistical tests were evaluated at a significance level of $\alpha=0.05$ with Bonferroni corrections to control for multiple comparisons.

\section{RESULTS}

\section{DEMOGRAPHICS}

Responses were recorded from 1202 sports medicine clinicians. The majority $(75 \%$; 897/1202) of respondents who indicated they met our inclusion criteria and provided consent to participate in the study proceeded to complete the survey. Nine respondents who indicated that they did not practice within a primary specialty of orthopaedic surgery, primary care sports medicine, physical therapy, or athletic training were excluded. The remaining 888 participants included 170 orthopaedic surgeons (88\% shoulder specialists), 108 primary care sports medicine physicians, 379 physical therapists, and 231 athletic trainers (Table 1).

Orthopaedic surgeons and physical therapists most com-

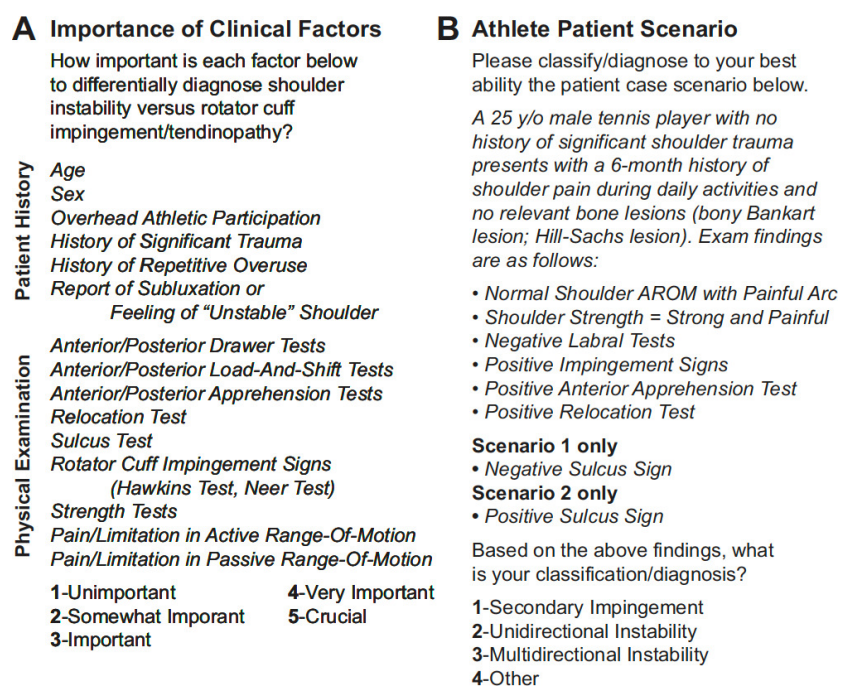

Figure 1. Summary of survey questions assessing the diagnosis of shoulder instability among physicians and rehabilitation providers.

monly worked in private practice. Primary care sports medicine physicians most commonly practiced in academic medical centers. Athletic trainers most commonly practiced in "other" settings. "Other" practice settings across all specialties included the treatment of military, athletic (high school, collegiate, and professional), outpatient, and educational (secondary and post-secondary) patient populations.

\section{IMPORTANCE OF CLINICAL FACTORS IN DIAGNOSIS OF SHOULDER INSTABILITY}

The importance of clinical factors used to differentiate shoulder instability from rotator cuff impingement differed between physicians and rehabilitation providers (Figure 2). All specialties reported that subluxation is important to the diagnosis of shoulder instability, rating it as their highest or second-highest overall factor (Table 2). However, physicians (orthopaedic surgeons, primary care sports medicine physicians) tended to consider physical examination clinical factors more important to diagnose shoulder instability whereas rehabilitation providers (physical therapists, athletic trainers) valued patient history factors. Both orthopaedic surgeons and primary care sports medicine physicians ranked apprehension tests and relocation tests as their highest and third-highest clinical factors, respectively. Apprehension tests were rated significantly higher by orthopaedic surgeons than by physical therapists and athletic trainers (both $P<0.001$ ). Further, relocation tests were rated significantly higher by both physician specialties than by physical therapists and athletic trainers (all $P \leqslant 0.008$ ). In contrast, physical therapists and athletic trainers ranked history of significant trauma and history of repetitive overuse, two patient history factors, among their top three clinical factors used to differentiate shoulder instability from impingement. Both rehabilitation provider specialties rated history of repetitive overuse significantly higher than orthopaedic surgeons (both $P<0.001$ ), and rehabilitation providers rated history of significant trauma significantly 
Table 1. Demographic information and clinical practice characteristics of survey respondents stratified by clinical specialty.

\begin{tabular}{|c|c|c|c|c|c|}
\hline & & \multicolumn{4}{|c|}{ SPECIALTY } \\
\hline & & $\begin{array}{l}\text { Orthopaedic } \\
\text { Surgery }\end{array}$ & $\begin{array}{l}\text { Primary Care } \\
\text { Sports Medicine }\end{array}$ & $\begin{array}{l}\text { Physical } \\
\text { Therapy }\end{array}$ & $\begin{array}{l}\text { Athletic } \\
\text { Training }\end{array}$ \\
\hline & $\begin{array}{l}\text { Total } \\
N(\%)\end{array}$ & $170(19.1 \%)$ & $108(12.2 \%)$ & $\begin{array}{c}379 \\
(42.7 \%) \\
\end{array}$ & $\begin{array}{c}231 \\
(26.0 \%) \\
\end{array}$ \\
\hline \multirow{5}{*}{\multicolumn{2}{|c|}{$\begin{array}{c}\text { Subspecialty } \\
N(\%)\end{array}$}} & \multirow{2}{*}{$\begin{array}{c}\text { Shoulder } \\
\text { Specialist: } \\
149(87.6 \%)\end{array}$} & $\begin{array}{c}\text { Emergency Medicine: } 2 \\
(1.9 \%)\end{array}$ & & \\
\hline & & & Family Medicine: 55 (50.9\%) & & \\
\hline & & \multirow{3}{*}{$\begin{array}{l}\text { Other/No } \\
\text { Specialty: } \\
21(12.4 \%)\end{array}$} & Internal Medicine: 7 (6.5\%) & & \\
\hline & & & Pediatrics: 14 (13.0\%) & & \\
\hline & & & PM\&R: 30 (27.8\%) & & \\
\hline \multirow{4}{*}{$\begin{array}{l}\text { Setting } \\
N(\%)\end{array}$} & $\begin{array}{r}\text { Academic Medical } \\
\text { Center }\end{array}$ & $55(32.4 \%)$ & $51(47.2 \%)$ & $63(16.6 \%)$ & 48 (20.8\%) \\
\hline & Community Hospital & $20(11.8 \%)$ & $10(9.3 \%)$ & $79(20.8 \%)$ & $18(7.8 \%)$ \\
\hline & Private Practice & $93(54.7 \%)$ & $37(34.3 \%)$ & $\begin{array}{c}186 \\
(49.1 \%) \\
\end{array}$ & $27(11.7 \%)$ \\
\hline & Other & $2(1.2 \%)$ & $10(9.3 \%)$ & $51(13.5 \%)$ & $\begin{array}{c}138 \\
(59.7 \%) \\
\end{array}$ \\
\hline \multirow{3}{*}{$\begin{array}{l}\text { Sex } \\
N(\%)\end{array}$} & Female & $7(4.2 \%)$ & $34(31.5 \%)$ & $\begin{array}{c}147 \\
(39.0 \%)\end{array}$ & $126(54.5)$ \\
\hline & Male & $158(94.1 \%)$ & $71(65.7 \%)$ & $\begin{array}{c}225 \\
(59.7 \%)\end{array}$ & $97(42.0 \%)$ \\
\hline & Prefer Not to Specify & $3(1.2 \%)$ & $2(1.9 \%)$ & $5(1.3 \%)$ & $8(3.5 \%)$ \\
\hline \multicolumn{2}{|c|}{$\begin{array}{c}\text { Years of Experience in } \\
\text { Primary Practice Area } \\
\text { mean } \pm S . D \text {. years }\end{array}$} & $18.1^{\mathrm{a}} \pm 11.1$ & $13.9^{\mathbf{b}} \pm 10.1$ & $\begin{array}{c}14.7^{\mathbf{b}} \pm \\
11.3\end{array}$ & $14.7^{b} \pm 7.9$ \\
\hline
\end{tabular}

a-byears of experience that do not share the same superscript letter in each row differ at $P<0.05$.

higher than primary care sports medicine physicians $(P=0.005-0.017)$. The main exception to this trend was age; both physician specialties rated age significantly higher than both rehabilitation provider specialties $(P \leqslant 0.006)$. No differences were noted between any clinical specialties on the three physical exam tests used to assess glenohumeral joint laxity (load and shift tests, sulcus test, drawer tests); no specialty rated one of these tests any higher than sixth overall (Table 2).

\section{CLINICAL SCENARIO DIAGNOSIS}

When diagnosing the young athlete in scenario 1 , whose physical exam findings included positive apprehension and relocation tests, positive impingement signs, and a negative sulcus sign, most clinicians chose either secondary impingement or unidirectional instability (Figure 3A). The responses from orthopaedic surgeons in scenario 1 differed significantly from all other specialties, leaning towards a diagnosis of secondary impingement (62\% vs. $48-54 \%$ secondary impingement, $29 \%$ vs. $35-42 \%$ unidirectional instability; all $P \leqslant 0.001)$. The change of the sulcus sign from negative to positive in scenario 2 prompted a majority of clinicians to select multidirectional instability, a significant change from scenario 1 across all specialties (orthopaedic surgeons: $1 \%$ in scenario 1 vs. $64 \%$ in scenario 2 ; primary care sports medicine physicians: $6 \%$ vs. $70 \%$; physical therapists: $3 \%$ vs. $68 \%$; athletic trainers: $8 \%$ vs. $75 \%$; all $P<0.001$; Figure 3B). Orthopaedic surgeons' responses in scenario 2 differed from rehabilitation providers, favoring multidirectional instability the least (both $P \leqslant 0.001$ ). The distribution of responses in either scenario did not differ between practice settings within any of the clinical specialties (scenario 1 : $P \geqslant 0.45$; scenario 2 : $P \geqslant 0.46$ ). "Other" diagnoses in scenario 1 included alternative rotator cuff pathologies, labral tears, and combinations of impingement and instability. "Other" diagnoses in scenario 2 primarily included combinations of impingement and instability. Participants reported a median of $10-30 \%$ and $5-20 \%$ of their new patient encounters with shoulder pain presented similarly to scenario 1 and scenario 2, respectively (Figure 3C). 


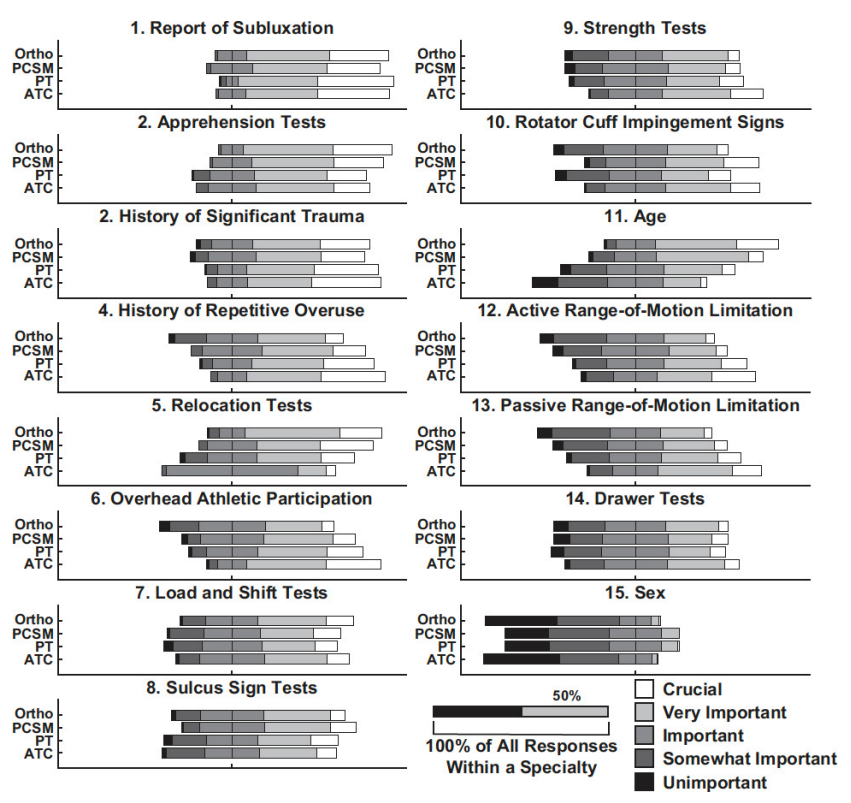

Figure 2. Rated importance of clinical factors to differentially diagnose shoulder instability versus rotator cuff impingement.

Ratings are depicted as a proportion of all responses for a single clinical factor within a specialty. Clinical factors are ordered (1-15) based on unweighted averages across all four specialties. Clinical Specialty: Ortho $=$ Orthopaedic Surgery; PCSM = Primary Care Sports Medicine; PT = Physical Therapy; ATC = Athletic Training. 


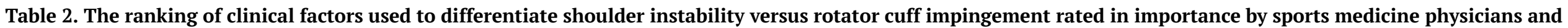
rehabilitation providers.

\begin{tabular}{|c|c|c|c|c|c|c|c|c|c|c|}
\hline \multirow{2}{*}{$\begin{array}{l}\text { Clinical Factor } \\
\qquad \text { Report of Subluxation }\end{array}$} & \multicolumn{2}{|c|}{$\begin{array}{l}\text { Orthopaedic Surgery } \\
\qquad\left(\mathrm{N}=120^{\wedge}\right)\end{array}$} & \multicolumn{2}{|c|}{$\begin{array}{l}\text { Primary Care Sports Medicine } \\
\qquad(N=108)\end{array}$} & \multicolumn{2}{|c|}{$\begin{array}{l}\text { Physical Therapy } \\
\qquad(\mathrm{N}=379)\end{array}$} & \multicolumn{2}{|c|}{$\begin{array}{l}\text { Athletic Training } \\
\qquad(\mathrm{N}=231)\end{array}$} & \multicolumn{2}{|c|}{$\begin{array}{c}\text { All } \\
\left(\mathrm{N}=838^{\wedge}\right)\end{array}$} \\
\hline & $2^{a, b}$ & $4.14 \pm 0.07$ & $2^{b}$ & $4.00 \pm 0.08$ & $1^{a}$ & $4.29 \pm 0.04$ & $1^{a, b}$ & $4.23 \pm 0.05$ & $1^{*}$ & $4.17 \pm 0.06$ \\
\hline Apprehension Tests & $1^{\mathrm{a}}$ & $4.18 \pm 0.06$ & $1^{\mathrm{a}, \mathrm{b}}$ & $4.03 \pm 0.07$ & $4^{c}$ & $3.75 \pm 0.05$ & $5^{b, c}$ & $3.79 \pm 0.06$ & $2^{\ddagger}$ & $3.94 \pm 0.06$ \\
\hline History of Significant Trauma & $5^{\mathrm{a}, \mathrm{b}}$ & $3.84 \pm 0.09$ & $4^{b}$ & $3.74 \pm 0.10$ & $2^{\mathrm{a}}$ & $4.04 \pm 0.05$ & $3^{\mathrm{a}}$ & $4.12 \pm 0.06$ & $2^{*}$ & $3.94 \pm 0.08$ \\
\hline History of Repetitive Overuse & $8^{c}$ & $3.34 \pm 0.09$ & $5^{b, c}$ & $3.71 \pm 0.08$ & $3^{b}$ & $3.91 \pm 0.05$ & $2^{\mathrm{a}}$ & $4.13 \pm 0.05$ & $4^{\ddagger}$ & $3.77 \pm 0.07$ \\
\hline Relocation Tests & $3^{a}$ & $3.95 \pm 0.08$ & $3^{a}$ & $3.93 \pm 0.09$ & $6^{\mathrm{b}}$ & $3.57 \pm 0.05$ & $12^{\mathrm{C}}$ & $3.25 \pm 0.04$ & $5^{\ddagger}$ & $3.67 \pm 0.07$ \\
\hline Overhead Athletic Participation & $10^{c}$ & $3.18 \pm 0.09$ & $9^{b, c}$ & $3.51 \pm 0.09$ & $5^{\mathrm{b}}$ & $3.69 \pm 0.05$ & $4^{a}$ & $4.01 \pm 0.06$ & $6^{\ddagger}$ & $3.60 \pm 0.07$ \\
\hline Load and Shift Tests & $6^{\mathrm{a}}$ & $3.54 \pm 0.09$ & $10^{\mathrm{a}}$ & $3.39 \pm 0.10$ & $11^{\mathrm{a}}$ & $3.29 \pm 0.05$ & $10^{\mathrm{a}}$ & $3.46 \pm 0.06$ & 7 & $3.42 \pm 0.08$ \\
\hline Sulcus Sign Tests & $7^{a}$ & $3.36 \pm 0.08$ & $7^{\mathrm{a}}$ & $3.57 \pm 0.09$ & $9^{a}$ & $3.33 \pm 0.06$ & $11^{\mathrm{a}}$ & $3.28 \pm 0.07$ & 8 & $3.38 \pm 0.08$ \\
\hline Strength Tests & $9^{b}$ & $3.22 \pm 0.09$ & $11^{\mathrm{b}}$ & $3.22 \pm 0.10$ & $8^{b}$ & $3.34 \pm 0.05$ & $6^{\mathrm{a}}$ & $3.64 \pm 0.06$ & $9 \ddagger$ & $3.35 \pm 0.08$ \\
\hline Rotator Cuff Impingement Signs & $11^{\mathrm{b}}$ & $3.08 \pm 0.09$ & $6^{\mathrm{a}}$ & $3.59 \pm 0.10$ & $13^{b}$ & $3.15 \pm 0.06$ & $9^{a}$ & $3.58 \pm 0.06$ & $10^{\ddagger}$ & $3.35 \pm 0.08$ \\
\hline Age & $4^{\mathrm{a}}$ & $3.87 \pm 0.08$ & $8^{a}$ & $3.52 \pm 0.09$ & $12^{\mathrm{b}}$ & $3.17 \pm 0.05$ & $14^{\mathrm{C}}$ & $2.70 \pm 0.07$ & $11^{\ddagger}$ & $3.31 \pm 0.07$ \\
\hline Active Range-of-Motion Limitation & $13^{\mathrm{C}}$ & $2.88 \pm 0.09$ & $13^{b, c}$ & $3.06 \pm 0.10$ & $7^{\mathrm{a}}$ & $3.40 \pm 0.05$ & $8^{a, b}$ & $3.59 \pm 0.20^{\wedge}$ & $12^{\ddagger}$ & $3.23 \pm 0.12$ \\
\hline Passive Range-of-Motion Limitation & $14^{\mathrm{C}}$ & $2.83 \pm 0.09$ & $12^{b, c}$ & $3.07 \pm 0.10$ & $10^{b}$ & $3.31 \pm 0.05$ & $7^{\mathrm{a}}$ & $3.60 \pm 0.06$ & $13^{\ddagger}$ & $3.20 \pm 0.08$ \\
\hline Drawer Tests & $12^{\mathrm{a}}$ & $3.04 \pm 0.10$ & $13^{\mathrm{a}}$ & $3.06 \pm 0.10$ & $14^{\mathrm{a}}$ & $3.05 \pm 0.05$ & $13^{\mathrm{a}}$ & $3.24 \pm 0.06$ & 14 & $3.10 \pm 0.08$ \\
\hline Sex & $15^{\mathrm{b}}$ & $1.88 \pm 0.08$ & $15^{\mathrm{a}}$ & $2.25 \pm 0.09$ & $15^{\mathrm{a}}$ & $2.26 \pm 0.05$ & $15^{\mathrm{b}}$ & $1.83 \pm 0.06$ & $15^{\ddagger}$ & $2.06 \pm 0.07$ \\
\hline
\end{tabular}

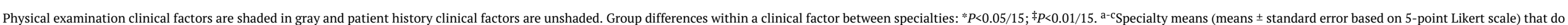

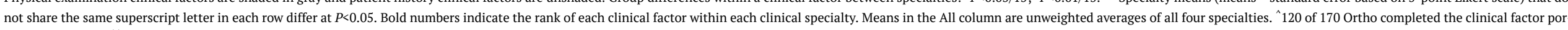
tion of the survey. ^ 32 of $231 \mathrm{ATC}$ rated the importance of active range-of-motion limitation. 


\section{DISCUSSION}

The goal of this study was to explore potential differences in clinical perspectives among physicians and rehabilitation providers in criteria used to diagnose shoulder instability. We accomplished this goal by surveying clinicians about the importance of common clinical factors to diagnosing shoulder instability and differentiating it from rotator cuff impingement. Overall, physicians differed from rehabilitation providers in how they rated the importance of these clinical factors, confirming our primary hypothesis. Physicians preferred physical examination factors, whereas rehabilitation providers instead preferred patient history factors as discussed in further detail below. Additionally, we surveyed sports medicine clinicians about the diagnosis they would choose for clinical scenarios with concurrent clinical findings of atraumatic shoulder instability and rotator cuff impingement. The results of this study indicate in this particular patient scenario that clinicians were split in diagnosing patients with secondary impingement or unidirectional instability when positive impingement signs, a positive apprehension test, and a negative sulcus sign were present. These differences in diagnostic labels can be confusing to the athlete seeking care, and they ultimately may delay the effectiveness of patient recovery. With the addition of a positive sulcus sign to an otherwise identical clinical scenario, the majority of clinicians chose a diagnosis of multidirectional instability. This finding demonstrates the universal importance of the sulcus sign in the diagnosis of multidirectional instability. Orthopaedic surgeons differed from other specialties in both scenarios, preferring impingement-focused instead of instability-focused diagnostic labels.

\section{DIFFERENCES IN RATINGS OF CLINICAL FACTORS USED TO DIFFERENTIATE SHOULDER INSTABILITY FROM IMPINGEMENT}

The tendency of orthopaedic surgeons and primary care sports medicine physicians to rate the apprehension and relocation tests as two of the most important factors suggests both specialties recognize the high specificity of these tests to rule in shoulder instability. ${ }^{26}$ When both positive, the apprehension and relocation tests have high sensitivity (81\%) and specificity (98\%) in diagnosing anterior shoulder instability. ${ }^{27}$ Physical therapists and athletic trainers rated the apprehension test among their top five factors as well, yet athletic trainers rated the relocation test noticeably lower than all other specialties. While over $55 \%$ of orthopaedic surgeons, primary care sports medicine physicians, and physical therapists rated the relocation as "Very Important" or "Crucial" to making their diagnosis, only $23 \%$ of athletic trainers answered similarly. Additional education may be warranted across disciplines on the value of the relocation test when used in combination with the apprehension test to diagnose shoulder instability.

As part of their role on sports medicine team, team physician responsibilities include many components that require managing patients during a snapshot of their athletic participation; examples include pre-participation evaluations, patient visits to the clinic after injury, and the

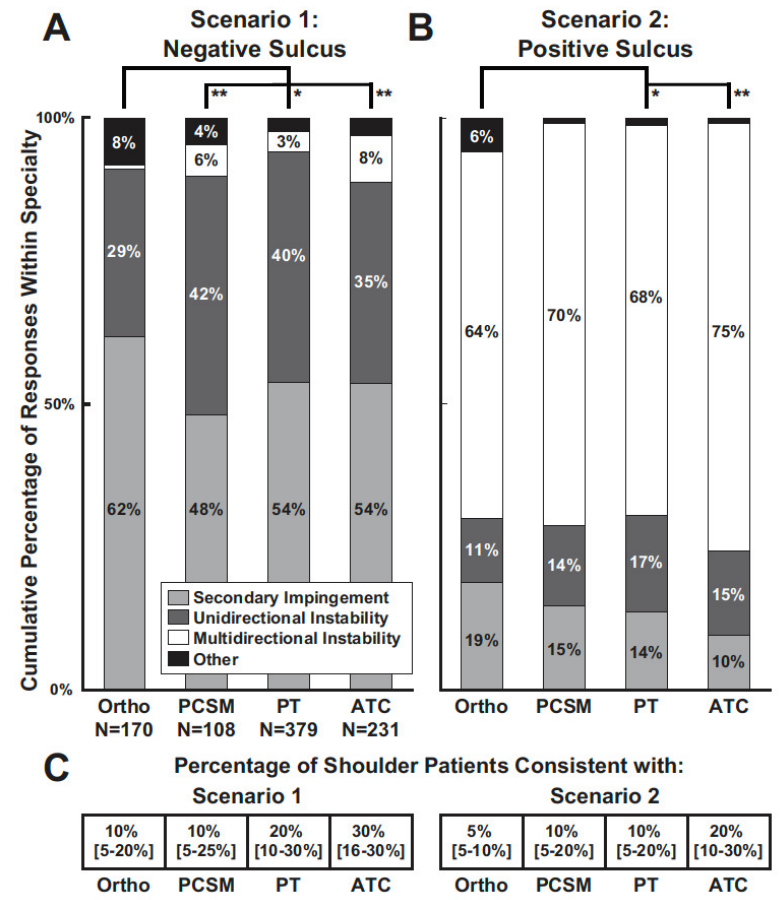

Figure 3. Diagnostic labels for two athlete scenarios with concurrent clinical examination findings of atraumatic shoulder instability and rotator cuff impingement.

\begin{abstract}
A-B) Scenarios 1 and 2 only differ by the presence of a negative or positive sulcus sign, respectively. C) Percentage of new encounters with shoulder pain with signs and symptoms consistent with each athlete scenario who present to each specialty (median [interquartile range]). Differences in the distributions of scenario diagnoses between specialties: ${ }^{*} P=0.001$; ${ }^{* *} P<0.001$. Clinical Specialty: Ortho $=$ Orthopaedic Surgery; PCSM = Primary Care Sports Medicine; $\mathrm{PT}=$ Physical Therapy; ATC $=$ Athletic Training.
\end{abstract}

management of injuries on the field. ${ }^{28}$ Given the importance of physical examinations tests to evaluate athletes during individual encounters, this pattern of care may explain their bias towards prioritizing physical examination tests over patient history factors in the differentiation of shoulder instability versus impingement. Interestingly, the responses from primary care sports medicine physicians were very similar to the responses from orthopaedic surgeons despite the former specialty containing multiple subcategories of physicians that manage patients which fall within different demographic groups. On the contrary, the role of rehabilitation providers within the sports medicine team corresponds to more longitudinal interactions with the athletes they are tasked with treating. Athletic trainers specifically interact with an athlete in many circumstances before an injury may occur, such as establishing procedures for safe strengthening, conditioning, and practicing. ${ }^{19}$ Athletic trainers spend a substantial amount of time with the athlete, which may explain why they rated two patient history factors, history of repetitive overuse and overhead athletic participation, higher than any other specialty. Following an injury, physical therapists are likewise tasked with spending considerable time working directly with athletes throughout their rehabilitation and guiding their return to sport. ${ }^{29}$ In turn, they also may be more attune to anecdotal relationships between the clinical history of the athlete and 
the development of symptoms, which may affect their preference towards rating patient history factors so highly.

\section{THE SULCUS SIGN AND THE DIAGNOSIS OF ATRAUMATIC MULTIDIRECTIONAL INSTABILITY}

Our results highlight the importance clinicians place on the sulcus sign when diagnosing atraumatic instability despite the debate over its utility as a marker of inferior laxity versus a diagnostic tool for shoulder instability. ${ }^{17,30}$ The addition of a positive sulcus sign to scenario 2 , which was otherwise identical to the scenario 1, prompted a large shift in diagnoses among all specialties from unidirectional instability and secondary impingement to multidirectional instability. These results align with a common classification of shoulder instability, which suggests multidirectional instability is present with a positive sulcus sign coupled with a positive provocative test for anterior or posterior instability (e.g. apprehension test). ${ }^{11,31}$ Further, clinicians reported using the sulcus sign to differentiate between multidirectional instability and unidirectional instability or secondary impingement despite placing less importance on the sulcus sign to differentiate between instability and impingement compared to other clinical factors.

Authors of previous studies, which have highlighted discrepancies in the diagnosis of atraumatic shoulder instability, expressed concern over the use of the sulcus sign when evaluating for shoulder instability; they suggested only associating a positive sulcus sign with inferior instability if symptoms are present with inferior laxity. ${ }^{17,30}$ Commonly, clinical laxity tests used to assess excessive glenohumeral translation are positive regardless of whether symptoms of pain or apprehension are provoked. ${ }^{32}$ Unfortunately, no specific provocative tests for inferior instability have since been designed for use in clinical practice, likely due to the low incidence of isolated inferior instability among athletes ${ }^{33}$ and the general population. ${ }^{34}$ Apprehension tests are instead only equipped to probe for symptoms of instability in the anterior and posterior directions. Indeed, certain studies including patients with multidirectional instability do describe symptomatic inferior laxity as part of their inclusion criteria, but they fail to attribute inferior symptoms to any physical examination technique. ${ }^{12,35}$ Observing the reproduction of instability symptoms in addition to excessive translation when grading tests for inferior instability has been advocated, ${ }^{30,36}$ given the value assigned to provocative tests when diagnosing shoulder instability. ${ }^{9}$

\section{CLINICAL IMPLICATIONS}

Consistency in the diagnosis of shoulder instability is critical to optimal interdisciplinary care of the athlete. The development of clinical guidelines for the diagnosis and treatment of shoulder instability may help increase consistency among all sports medicine clinicians. These guidelines should be organized by an interdisciplinary team of sports medicine clinicians, as have been developed for shoulder pathologies such as rotator cuff injuries and glenohumeral osteoarthritis. ${ }^{37,38}$ Such guidelines should build on current patient care pathways for atraumatic shoulder instability 39,40 and clarify the collective impor- tance of different physical examination and patient history factors towards making a diagnosis of athletes' shoulder pain. Clarifying the role of the sulcus sign in the assessment of atraumatic shoulder instability may also be warranted, given the large influence the sulcus sign plays among all sports medicine clinicians in the diagnosis of multidirectional instability. Additionally, interdisciplinary sports medicine conferences may help overcome differences in the education of musculoskeletal medicine recognized among different specialties and improve consistency in diagnostic language. ${ }^{41-43}$ Similar recommendations of collaboration have been advocated based on differences in opinion among orthopaedic surgeons and physical therapists in the role of rehabilitation following rotator cuff repair. ${ }^{44}$

\section{LIMITATIONS}

The use of a survey instrument is associated with both volunteer and recollection biases. However, the distribution of a survey via email to multiple professional clinical societies allowed for acquisition of responses from a large clinical cohort practicing in sports medicine that would otherwise be unattainable. Additional clinical factors potentially considered in the diagnosis of shoulder instability ${ }^{9,45,46}$ were not included in this study's rating of clinical factors and could have provided further insight into how clinicians diagnose the condition. Finally, the two scenarios used in this study were brief, not including all information that clinicians may have access to when assessing a patient. The two scenarios also included more physical examination findings than patient history factors, potentially limiting how rehabilitation providers could evaluate the scenario given the emphasis they placed on patient history factors to differentiate shoulder instability from rotator cuff impingement. Additional clinical, radiographic, and demographic information was withheld to avoid creating a scenario too specific to generalize to broader cases of atraumatic shoulder instability.

\section{CONCLUSION}

Sports medicine clinicians differed between different specialties in the clinical factors believed to be important to diagnose shoulder instability in athletes. Furthermore, agreement on the diagnostic labels used with athletes that present with clinical findings of atraumatic shoulder instability is lacking. More consensus is warranted to improve the consistency of clinical factors used to diagnose shoulder instability and differentiate this from concurrent rotator cuff impingement findings. Shoulder instability clinical practice guidelines, consensus meetings, and interdisciplinary educational opportunities are needed to optimize care for athletes commonly treated by a variety of sports medicine specialties.

\section{ACKNOWLEDGEMENTS}

The authors would like to acknowledge Elizabeth A. Hahn for her assistance with the structural organization of the 
survey and Elise Cataldo Cirone for her assistance in survey design and data collection.

\section{CONFLICTS OF INTEREST}

ALS reports grants from the Foundation for Physical Therapy Research and the National Institutes of Health (NICHD 1R01HD098698-01, AHQR 1R01HS027426-01, NCATS UL1TR001422) outside of the submitted work. ALS also serves on the Board of Directors for the American Society of Shoulder and Elbow Therapists, on the Editorial Board for the Journal Orthopaedic and Sports Physical Therapy, and as Vice Chair of the Research Committee for the Academy of Orthopaedic Physical Therapy. XL reports consultant fees, royalties, I.P., and non-financial support from FH Ortho and consultant fees from Mitek-Depuy outside of the submitted work. XL also serves on the Editorial Board for the American Journal Sports Medicine, on the Editorial Board for Orthopedics Review, on the Research Committee for the American Society Shoulder and Elbow Surgeons, and as Sports Medi- cine and Arthroscopy ICL Chair for the American Academy of Orthopedic Surgery. GM reports royalties from Zimmer Biomet outside of the submitted work. For the remaining authors, none were declared.

\section{SOURCES OF FUNDING}

This work was supported in part by the National Institutes of Health (NIAMS F31AR074288, NIGMS T32GM008152), Northwestern University, the American Academy of Sports Physical Therapy, the Academy of Orthopaedic Physical Therapy, and the American Physical Therapy Association. The content is solely the responsibility of the authors and does not necessarily represent the official views of the $\mathrm{Na}-$ tional Institutes of Health.

Submitted: December 18, 2020 CDT, Accepted: March 18, 2021 CDT 


\section{REFERENCES}

1. Lippitt SB, Harryman DT II, Sidles JA, Matsen FA III. Diagnosis and management of AMBRI syndrome. Tech Orthop. 1991;6(1):61-74. doi:10.1097/0001361 1-199103000-00011

2. Owens BD, Agel J, Mountcastle SB, Cameron KL, Nelson BJ. Incidence of glenohumeral instability in collegiate athletics. Am J Sports Med. 2009;37(9):1750-1754. doi:10.1177/036354650933459 1

3. Caplan J, Julien TP, Michelson J, et al. Multidirectional instability of the shoulder in elite female gymnasts. Am J Orthop. 2007;36(12):660-665.

4. Bak K, Faunø P. Clinical findings in competitive swimmers with shoulder pain. Am J Sports Med. 1997;25(2):254-260. doi:10.1177/03635465970250022 1

5. Gross ML, Brenner SL, Esformes I, Sonzogni JJ. Anterior shoulder instability in weight lifters. Am J Sports Med. 1993;21(4):599-603. doi:10.1177/0363546 $\underline{59302100419}$

6. Lebar RD, Alexander AH. Multidirectional shoulder instability. Clinical results of inferior capsular shift in an active-duty population. Am J Sports Med. 1992;20(2):193-198. doi:10.1177/03635465920200021 $\underline{7}$

7. Owens BD, Duffey ML, Nelson BJ, DeBerardino TM, Taylor DC, Mountcastle SB. The incidence and characteristics of shoulder instability at the United States Military Academy. Am J Sports Med. 2007;35(7):1168-1173. doi:10.1177/036354650629517 $\underline{9}$

8. Finley MA, Rodgers MM. Prevalence and identification of shoulder pathology in athletic and nonathletic wheelchair users with shoulder pain: A pilot study. J Rehabil Res Dev. 2004;41(3B):395-402. d oi:10.1682/jrrd.2003.02.0022

9. Kuhn JE. A new classification system for shoulder instability. Br J Sports Med. 2010;44(5):341-346. doi:1 $\underline{0.1136 / \text { bjsm. } 2009.071183}$

10. Gaskill TR, Taylor DC, Millett PJ. Management of multidirectional instability of the shoulder. J Am Acad orthop Surg. 2011;19(12):758-767. doi:10.5435/001246 35-201112000-00006
11. Warby SA, Ford JJ, Hahne AJ, et al. Comparison of 2 exercise rehabilitation programs for multidirectional instability of the glenohumeral joint: a randomized controlled trial. Am J Sports Med. 2018;46(1):87-97. doi:10.1177/0363546517734508

12. Misamore GW, Sallay PI, Didelot W. A longitudinal study of patients with multidirectional instability of the shoulder with seven- to ten-year follow-up. J Shoulder Elbow Surg. 2005;14(5):466-470. doi:10.1016/j.jse.2004.11.006

13. Pollock RG, Owens JM, Flatow EL, Bigliani LU. Operative results of the inferior capsular shift procedure for multidirectional instability of the shoulder. J Bone Joint Surg Am. 2000;82(7):919-928. ㅁ oi:10.2106/00004623-200007000-00003

14. Bigliani LU, Kurzweil PR, Schwartzbach CC, Wolfe IN, Flatow EL. Inferior capsular shift procedure for anterior-inferior shoulder instability in athletes. Am J Sports Med. 1994;22(5):578-584. doi:10.1177/0363546 59402200502

15. Bak K, Spring BJ, Henderson IJP. Inferior capsular shift procedure in athletes with multidirectional instability based on isolated capsular and ligamentous redundancy. Am J Sports Med. 2000;28(4):466-471. doi:10.1177/03635465000280040 $\underline{501}$

16. Baker CL III, Mascarenhas R, Kline AJ, Chhabra A, Pombo MW, Bradley JP. Arthroscopic treatment of multidirectional shoulder instability in athletes: a retrospective analysis of 2- to 5-year clinical outcomes. Am J Sports Med. 2009;37(9):1712-1720. do i: $10.1177 / 0363546509335464$

17. Chahal J, Kassiri K, Dion A, et al. Diagnostic and treatment differences among experienced shoulder surgeons for instability conditions of the shoulder. Clin J Sport Med. 2007;17(1):5-9. https://doi.org/10.10 97/jsm.0b013e31802b4fda.

18. Cerny FJ, Patton DC, Whieldon TJ, Roehrig S. An organizational model of sports medicine facilities in the United States. J Orthop Sports Phys Ther. 1992;15(2):80-86. doi:10.2519/jospt.1992.15.2.80

19. Courson R, Goldenberg M, Adams KG, et al. Interassociation consensus statement on best practices for sports medicine management for secondary schools and colleges. J Athl Train. 2014;49(1):128-137. doi:1 0.4085/1062-6050-49.1.06 
20. Tisano BK, Estes AR. Overuse Injuries of the pediatric and adolescent throwing athlete. Med Sci Sports Exerc. 2016;48(10):1898-1905. doi:10.1249/ms s.0000000000000998

21. McClure PW, Michener LA. Staged Approach for Rehabilitation Classification: Shoulder Disorders (STAR-Shoulder). Phys Ther. 2015;95(5):791-800. do $\mathrm{i}: 10.2522 /$ ptj.20140156

22. Jobe CM, Coen MJ, Screnar P. Evaluation of impingement syndromes in the overhead-throwing athlete. J Athl Train. 2000;35(3):293-299.

23. Harris PA, Taylor R, Minor BL, et al. The REDCap consortium: Building an international community of software platform partners. J Biomed Inform. 2019;95:103208. doi:10.1016/i.jbi.2019.103208

24. Harris PA, Taylor R, Thielke R, Payne J, Gonzalez $\mathrm{N}$, Conde JG. Research electronic data capture (REDCap)-A metadata-driven methodology and workflow process for providing translational research informatics support. J Biomed Inform. 2009;42(2):377-381. doi:10.1016/j.jbi.2008.08.010

25. Norman G. Likert scales, levels of measurement and the "laws" of statistics. Adv Health Sci Educ Theory Pract. 2010;15(5):625-632. doi:10.1007/s1045 9-010-9222-y

26. Hegedus EJ, Goode AP, Cook CE, et al. Which physical examination tests provide clinicians with the most value when examining the shoulder? Update of a systematic review with meta-analysis of individual tests. Br J Sports Med. 2012;46(14):964-978. doi:10.11 36/bjsports-2012-091066

27. Farber AJ, Castillo R, Clough M, Bahk M, McFarland EG. Clinical assessment of three common tests for traumatic anterior shoulder instability. $J$ Bone Joint Surg Am. 2006;88(7):1467-1474. doi:10.210 6/00004623-200607000-00006

28. Team Physician Consensus Statement. Medicine \& Science in Sports \& Exercise. 2000;32(4):877. doi:10.10 97/00005768-200004000-00023

29. American Board of Physical Therapy Specialties. Sports Physical Therapy Description of Specialty Practice. Alexandria VA: American Physical Therapy Association; 2013.

30. McFarland EG, Kim TK, Park HB, Neira CA, Gutierrez MI. The effect of variation in definition on the diagnosis of multidirectional instability of the shoulder. J Bone Joint Surg Am. 2003;85(11):2138-2144. doi:10.2106/00004623-20031 1000-00011
31. Kiss RM, Illyés Á, Kiss J. Physiotherapy vs. capsular shift and physiotherapy in multidirectional shoulder joint instability. J Electromyogr Kinesiol. 2010;20(3):489-501. doi:10.1016/j.jelekin.2009.09.001

32. Tzannes A, Murrell GAC. Clinical examination of the unstable shoulder. Sports Med. 2002;32(7):447-457. doi:10.2165/00007256-20023207 0-00004

33. Wagstrom E, Raynor B, Jani S, et al. Epidemiology of Glenohumeral Instability Related to Sporting Activities Using the FEDS (Frequency, Etiology, Direction, and Severity) Classification System: A Multicenter Analysis. Orthop J Sports Med. 2019;7(7):232596711986103. doi:10.1177/2325967119 $\underline{861038}$

34. Hettrich CM, Cronin KJ, Raynor MB, et al. Epidemiology of the Frequency, Etiology, Direction, and Severity (FEDS) system for classifying glenohumeral instability. J Shoulder Elbow Surg. 2019;28(1):95-101. doi:10.1016/j.jse.2018.08.014

35. Joseph TA, Williams JS Jr, Brems JJ. Laser capsulorrhaphy for multidirectional instability of the shoulder. An outcomes study and proposed classification system. Am J Sports Med. 2003;31(1):26-35. doi:10.1177/0363546503031001160 1

36. Hegedus EJ, Michener LA, Seitz AL. Three key findings when diagnosing shoulder multidirectional instability: patient report of instability, hypermobility, and specific shoulder tests. J Orthop Sports Phys Ther. 2020;50(2):52-54. doi:10.2519/josp t.2020.0602

37. American Academy of Orthopaedic Surgeons. Management of Glenohumeral Joint Osteoarthritis Evidence-Based Clinical Practice Guideline 2020.

38. American Academy of Orthopaedic Surgeons. Management of Rotator Cuff Injuries Clinical Practice Guideline 2019.

39. Noorani A, Goldring M, Jaggi A, et al. BESS/BOA patient care pathways: Atraumatic shoulder instability. Shoulder Elbow. 2019;11(1):60-70. doi:10.1 $177 / 1758573218815002$

40. Brownson P, Donaldson O, Fox M, et al. BESS/BOA Patient Care Pathways: Traumatic anterior shoulder instability. Shoulder Elbow. 2015;7(3):214-226. doi:1 $\underline{0.1177 / 1758573215585656}$

41. Freedman KB, Bernstein J. The adequacy of medical school education in musculoskeletal medicine. J Bone Joint Surg Am. 1998;80(10):1421-1427. doi:10.2106/00004623-19981 $\underline{0000-00003}$ 
42. Freedman KB, Bernstein J. Educational deficiencies in musculoskeletal medicine. J Bone Joint Surg Am. 2002;84(4):604-608. doi:10.2106/0000462 3-200204000-00015

43. Childs JD, Whitman JM, Sizer PS, Pugia ML, Flynn TW, Delitto A. A description of physical therapists' knowledge in managing musculoskeletal conditions. BMC Musculoskelet Disord. 2005;6(1):32. doi:10.1186/ 1471-2474-6-32
44. Kane LT, Lazarus MD, Namdari S, Seitz AL, Abboud JA. Comparing expert opinion within the care team regarding postoperative rehabilitation protocol following rotator cuff repair. J Shoulder Elbow Surg. 2020;29(9):e330-e337. doi:10.1016/j.jse.2020.01.097

45. Gross ML, Distefano MC. Anterior release test. A new test for occult shoulder instability. Clin Orthop Relat Res. 1997;(339):105-108. doi:10.1097/0000308 6-199706000-00014

46. Gagey OJ, Gagey N. The hyperabduction test. J Bone Joint Surg Br. 2001;83-B(1):69-74. doi:10.1302/0 $\underline{\text { 301-620x.83b1.0830069 }}$ 